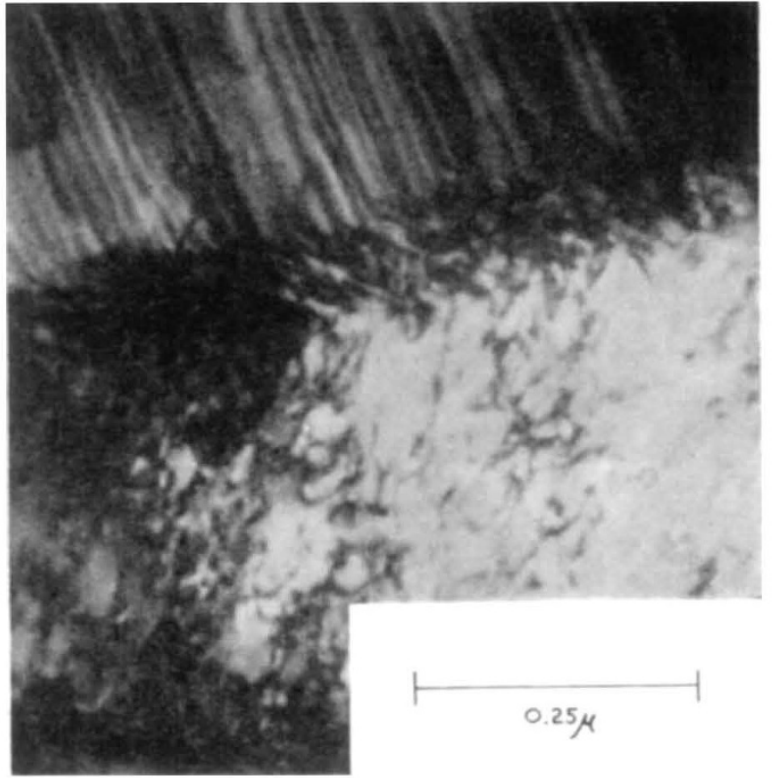

Fig. 4. Enlargement of habit plane at point $C$ in Fig. 2

Air Force Materials Laboratory, Research and Technology Division. We thank Dr. G. Thomas, University of California at Berkeley, for many helpful discussions.

Iowa State University,

B. G. KOEPKE

Ames, Iowa.

R. P. JEWETT

W. T. Chandler

Rocketdyne Division of North America Aviation, Ine., Canoga Park, California.

${ }^{1}$ Venables, J. A., Phil. Mag., 7, 35 (1962).

${ }^{2}$ Frank, F. C., Acta Met., 1, 15 (1953).

${ }^{3}$ Bogers, A. J., and Burgers, W. G., Acta Met., 12, 255 (1964).

${ }^{4}$ Lagneborg, R., Acta Met., 12, 823 (1964).

${ }^{5}$ Dieter, G. E., Strengthening Mechanisms in Solids, 302 (American Society tor Metals, Metals Park, Ohio, 1962).

\section{CHEMISTRY}

\section{Effect of Crack Propagation Velocity on the Fracture Surface Energy of Poly(methyl methacrylate)}

WE have measured values of the fracture surface energy $(\gamma)$ at $+20^{\circ} \mathrm{C}$ of a sample of high molecular weight poly (methyl methacrylate) sheet ('Perspex', manufactured by Imperial Chemical Industries, Ltd., Plasties Division). In order to measure $\gamma$ over a wide range of crack propa. gation velocities $(\dot{c})$, we used three different experimental techniques:

(1) A modification of the static loading method described by Van den Boogaart and Turner ${ }^{1}$ in which the erack length was measured as a function of time. From the results it was possible to deduce the relation between $\gamma$ and $\dot{c}$ by assuming a value for Young's modulus $(E=$ $\left.2.85 \times 10^{10} \mathrm{dynes} / \mathrm{cm}^{2}\right)$. This technique covered the range of velocities from comparatively slow rates $\left(\simeq 10^{-4} \mathrm{~cm} / \mathrm{sec}\right)$ up to about $1 \mathrm{~cm} / \mathrm{sec}$. Beyond this the crack propagation rate increased rapidly and the specimen failed catastrophically.

(2) A modification of the cleavage technique described by Broutman and MeGarry ${ }^{2}$ which produced controlled erack growth at various lead screw speods.

(3) Charpy impact tests on sharply notched specimens. $\gamma$ was taken as the ratio of the energy to break to the area of the new surfaces created during crack growth. Although $\dot{c}$ was not measured accurately, it is between the pendulum

$\begin{array}{ccc}\begin{array}{c}\text { Experimental } \\ \text { technique }\end{array} & \begin{array}{c}\text { Table } 1 \\ \text { Crack } \\ \text { propagation } \\ \text { velocity } \\ \text { (cm/sec) }\end{array} & \begin{array}{c}\text { Fracture } \\ \text { surface } \\ \text { energy } \\ \left(10^{\text {s }} \text { dynes } / \mathrm{cm}\right)\end{array} \\ 1 & 10^{-4} & 3 \cdot 65 \\ 2 & 7 \cdot 4 \times 10^{-4} & 3 \cdot 7 \\ 1 & 10^{-3} & 3 \cdot 65 \\ 2 & 6 \cdot 8 \times 10^{-3} & 3 \cdot 0 \\ 1 & 10^{-2} & 4 \cdot 0 \\ 1 & 3 \times 10^{-2} & 4 \cdot 75 \\ 2 & 3 \cdot 3 \times 10^{-2} & 5 \cdot 8 \\ 1 & 10^{-1} & 5 \cdot 5 \\ 2 & 1 \cdot 4 \times 10^{-1} & 5 \cdot 1 \\ 1 & 3 \times 10^{-1} & 6 \cdot 2 \\ 2 & 7 \cdot 6 \times 10^{-1} & 8 \cdot 9 \\ 2 & 4 \cdot 3 & 6 \cdot 8 \\ 2 & 33 & 5 \cdot 3 \\ 3 & >240 & 4 \cdot 5\end{array}$

velocity at the point of impact $(240 \mathrm{~cm} / \mathrm{sec})$ and the maximum possible crack propagation velocity $\left(\sim 10^{5}\right.$ $\mathrm{cm} / \mathrm{sec})$. Thus it is substantially higher than in the othor experiments.

The results are given in Table 1 .

The principal conclusion that can be drawn from these experiments is that $\gamma$, like all other mechanical properties of poly(methyl methacrylate), is rate-dependent. It would seem to have a maximum value of about $9 \times 10^{5} \mathrm{dynes} / \mathrm{cm}$ at about $1 \mathrm{~cm} / \mathrm{sec}$ at $+20^{\circ} \mathrm{C}$. This conclusion is qualitatively confirmed by the fact that crack propagation was stablo at all in the static loading experiment. Stable crack propagation, in this experiment, implies that $\gamma$ increases as $\dot{c}$ increases; a change to unstable, catast rophic erack propagation implies that a maximum value of $\gamma$ has been roached.

In the static loading experiment the change-over point from stable to unstable crack propagation is readily seen by examination of the fracture surface. This makes it possible to calculate $K_{c}$ by the equation given in ref. 1. $K_{c}$ can also be calculated from the cleavage experiments by assuming that the maximum value of $\gamma$ is $9 \times 10^{5}$ dynes $/ \mathrm{cm}$ and that $E$ is $2.85 \times 10^{10}$ dynes $/ \mathrm{cm}^{2} . K_{c}{ }^{2}=$ $E \gamma$ for plane stress. Both techniques give:

$$
K_{c}=1.6 \times 10^{8} \text { dynes } / \mathrm{cm}^{3 / 2}
$$

Another implication of these results is that $\gamma$ will be higher when measured on notched tension specimens than when measured in equilibrium cleavage experiments as found by $B$ rrry $^{3}$ for both poly(methyl methacrylate) and polystyrene.

It is well known that, however it is eharacterized and measured, the 'ductility' of poly (methyl methacrylate) increases as the temperature is raised above $+20^{\circ} \mathrm{C}$; it reaches a peak value and then decreases again with further increase in temperature. We suggost, therefore, that the cause of the rate-dependence of the fracture surface enorgy may be the heat produced by the localized 'plastic' deformation at the tip of the propagating crack. As the crack-propagation velocity increases, the process changes from isothermal to adiabatic. It follows that as the crack-propagation velocity increases, the temperature at the crack tip increases and thorefore the fracture surface energy first increases and then decreases.

\section{P. T. VINCENT}

Imperial Chemical Industries, Ltd., K. V. GOTHAM

Welwyn Garden City, Hertfordshire.

' Van den Boogaart, A., and Turner, C. E., Trans. J. Plast. Inst., 31, 109 (1963).

${ }^{2}$ Broutman, L. J., and MeGarry, F. J., J. App. Polymer Sci., 9, 589 (1965). ${ }^{3}$ Berry, J. P., Fracture Processes in Polymeric Solids, edit, by Rosen, 13. 221 (interseience, 1964).

\title{
Structure of Desmosine and Isodesmosine
}

IN 1963 Partridge, Elsden and Thomas ${ }^{1}$ reported the isolation of two new amino-acids named desmosine and isodesmosine from bovine ligamentum nuchae elastin. Since then the presence of these amino-acids has been demonstrated in elastins from various sources ${ }^{2}$. 